\title{
Identificação de Staphylococcus epidermidis em formigas (Hymenoptera: Formicidae) coletadas em uma área de alimentação no município de Guarulhos, São Paulo
}

\author{
Identification of Staphylococcus epidermidis on ants (Hymenoptera: \\ Formicidae) collected in a food court in the city of Guarulhos, São Paulo
}

\section{Carolyn Barbosa Carrecelli ${ }^{1}$, Denise Barcelos ${ }^{2 *}$}

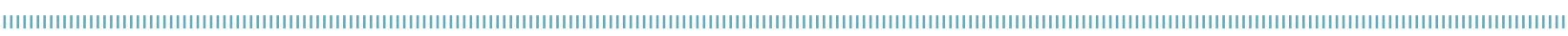

\begin{abstract}
RESUMO: Com o processo de urbanizaçáo, ocorreu aumento da disseminaçáo de doenças veiculadas por artrópodes, sendo os mais comuns as formigas. A presença delas é mais frequente pelo seu tamanho, por sua facilidade de locomoção e por sua forma de vida social. Assim, podem atuar como vetores mecânicos de bactérias endossimbiontes e patogênicas, ocasionando contaminação em alimentos e no ambiente hospitalar. Os objetivos deste artigo foram isolar e identificar bactérias contaminantes dos gêneros Escherichia sp., Staphylococcus sp. e Salmonella sp. em formigas operárias circulantes no entorno de uma lanchonete de intenso fluxo de pessoas. Foram coletados rastros de formigas no período vespertino, amostradas em quatro pontos do pátio no entorno da lanchonete. Após a coleta, as bactérias foram identificadas por cultivo em meio de cultura Caldo Triptona de Soja para enriquecimento e meios específicos. Dos quatro pontos coletados no entorno da lanchonete, dois apresentaram crescimento de Staphylococcus epidermidis. Este estudo identificou a presença de S. epidermidis em formigas operárias em uma lanchonete localizada em uma área de grande circulação de pessoas, indicando que elas podem ser vetores de contaminação em estabelecimentos de comércio de alimentos.
\end{abstract}

PALAVRAS-CHAVE: formigas; contaminação; Staphylococcus sp.; Staphylococcus epidermidis.

\begin{abstract}
Out of the urbanization process, there was an increase in the spread of diseases carried by arthropods, and the most common are the ants. Their presence is related to its size, ease of locomotion and form of social life. Therefore, they can act as mechanical vectors of obligatory endosymbiont bacteria and pathogen ones as food contamination, and contamination of hospital environment. The purposes of this article was to isolate and identify contaminating bacteria of the genera Escherichia sp., Staphylococcus sp. and Salmonella sp. on ants workers circulating around a diner of high movement of people. Ant tracks were collected in the afternoon, sampled at four points to around the patio of the cafe. After the collection, the bacteria were identified, by growing in culture medium for enrichment and Tryptic Soy Broth - specific means. Of the four collected points around the diner, two of them showed growth of Staphylococcus epidermidis. This study identified the presence $S$. epidermidis on ants workers vectors in a cafeteria located in an area of great movement of persons indicating that the ants can be vectors of contamination in food trade.
\end{abstract}

KEYWORDS: ants; contamination; Staphylococcus sp.; Staphylococcus epidermidis. 


\section{INTRODUÇÃO}

No Brasil, são catalogadas cerca de 2.000 espécies, das quais somente de 20 a 30 são consideradas pragas urbanas (CHADEE; LE MAITRE, 1990). As formigas são insetos altamente sociais, caracterizados pela presença de várias geraçóes convivendo em um mesmo período dentro do ninho, pelo cuidado com a prole e por meio da divisão de trabalho. Além disso, as formigas diferem dos demais insetos sociais por apresentarem dieta alimentar muito diversificada (BOURSAUX-EUDE; GROSS, 2000; BUENO; CAMPOS-FARINHA, 1999).

Com o processo de urbanização, houve aumento da disseminação de doenças veiculadas por artrópodes, e os mais comuns são as formigas. A presença delas em ambiente urbano está relacionada ao seu tamanho, à sua facilidade de locomoção e à sua forma de vida social (PESQUERO et al., 2008).

Trabalhos afirmam que as formigas podem atuar tanto como vetores de bactérias endossimbiontes, quanto como bactérias patogênicas (DA COSTA et al., 20096). Essa transmissão está associada a variadas situaçóes, como alimentos estocados e lixo (caseiro, hospitalar e em geral) em ambientes de grande circulação (FONTANA et al., 2010; SALYER; BENNETT; BUCZKOWSKI, 2014). Além disso, em razão da sua facilidade de adaptação, elas se beneficiam da convivência humana, causando grande risco para a saúde pública, principalmente se não forem controladas (BUCZKOWSKI; RICHMOND, 2012).

Formigas andarilhas ou "tramp species" transportam bactérias presentes de um ambiente para outro, permitindo que elas se desenvolvam em diversos lugares, entre eles os hospitais, além de atuarem como carregadoras de bactérias patogênicas (BRAGANÇA; LIMA, 2010). Os agentes mais comuns de contaminação em ambiente hospitalar são Staphylococcus sp. (MÁXIMO et al., 2014) e Escherichia coli (CERVA et al., 2014).

A contaminação por Staphylococcus aureus pode ocorrer por manipuladores de alimentos que alojam essas bactérias no nariz, na garganta ou na superfície das mãos (LAMBRECHTS et al., 2014; HO et al., 2015). Os principais sintomas (náuseas, vômitos, dores abdominais e diarreia) aparecem entre 2 a 6 horas após a ingestão do alimento contaminado (DE WIT; KAMPELMACHER, 1988).

Em hospitais, bactérias do gênero Staphylococcus sp. constituem-se como o principal micro-organismo causador de infecção de feridas cirúrgicas e o mais comum agente de infecção hospitalar. Pelo fato de muitas cepas serem resistentes à maioria dos antibióticos disponíveis, sua ocorrência é de preocupação mundial (FONTANA et al., 2010; MIRZAEI et al., 2014). Staphylococcus epidermidis também é causadora de infecçóes crônicas em ambiente hospitalar associadas às formigas. Esse tipo de contaminação pode desenvolver endocardite em pacientes (SAITO et al., 2014).

Pertencente ao grupo dos coliformes fecais, Escherichia coli é um micro-organismo indicador de contaminação, podendo atuar como organismo comensal, patógeno oportunista e patógeno extremamente especializado (GIL et al., 2014). O gênero Salmonella inclui várias espécies patogênicas para o homem e outros animais, além de estar associado à contaminação de hospitais e alimentos (PESQUERO et al., 2008).

Sabendo-se do potencial de atuação das formigas como vetores mecânicos de organismos patogênicos e de outros contaminantes, este trabalho propôs a identificação de Escherichia sp., Staphylococcus sp. e Salmonella sp. presentes em formigas operárias circulantes no entorno de uma lanchonete de uma área de convivência com grande fluxo de pessoas.

\section{MATERIAL E MÉTODOS}

A pesquisa foi realizada em abril de 2014, no entorno de uma lanchonete localizada na Universidade Guarulhos (UnG), no município de Guarulhos, São Paulo. Para determinar o local de coletas, foi realizado um estudo prévio das áreas nas quais havia circulação de formigas, o que possibilitou identificar os locais em que poderiam ocorrer formigueiros.

As coletas foram realizadas no período vespertino, amostradas em quatro pontos do pátio no entono da lanchonete. A identificação do gênero e da espécie das formigas coletadas não aconteceu neste trabalho.

Foram montadas armadilhas com uma folha de papel-filtro estéril $5 \times 5 \mathrm{~cm}$ contendo, na região central, uma isca. Esta folha foi colocada sob outra folha de papel-filtro estéril $10 \times 10 \mathrm{~cm}$ (Fig. 1A) em lugares estratégicos na proximidade da lanchonete estudada. Para garantir menor risco de contaminação, as folhas para montagem da armadilha foram colocadas em um cartão de papel kraft lacrado com fita de autoclave e submetido à clavagem a $121^{\circ} \mathrm{C}$ por 15 minutos antes da exposição (Fig. 1B).

O local escolhido para coleta era de formato retangular, e os pontos escolhidos representaram os cantos desse espaço, sendo numerados da seguinte maneira: Ponto 1, Ponto 2, Ponto 3 e Ponto 4. Foram oferecidos cerca de $2 \mathrm{~mL}$ de mel como isca na folha A $(5 \times 5 \mathrm{~cm})$ das armadilhas (Fig. 2A). Em todos os pontos, após o período de 1 hora de observação, com o swab estéril umedecido em solução salina $0,9 \%$ estéril, foram coletadas
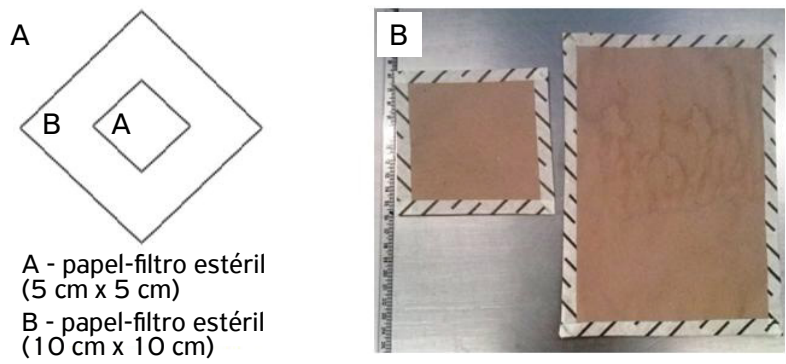

Figura 1. (A) Esquema ilustrativo das armadilhas utilizadas; (B) cartão de esterilização utilizado para autoclavagem. 
amostras da área em que as formigas circularam sob o papel-filtro A, sem encostar na isca, conforme Figura 2B, inoculadas no meio de cultura Caldo Triptona de Soja e enviadas para estufa a $37^{\circ} \mathrm{C}$, de 24 a 48 horas. Após crescimento em meio de cultura líquido Caldo Triptona de Soja, as amostras foram semeadas no meio ágar TSA (Ágar Triptona de Soja - Kasvi) pelo método de esgotamento e enviadas novamente para estufa a $37^{\circ} \mathrm{C}$, de 24 a 48 horas. Foi realizada a diferenciação pelo método de Gram. Depois, as amostras foram ressemeadas em meio de cultura Caldo Triptona de Soja, para enriquecimento, e levadas para estufa a $37^{\circ} \mathrm{C}$, de 24 a 48 horas (Figs. 3A e 3B). Após essa etapa de enriquecimento em Caldo Triptona de Soja, todas foram semeadas pelo método de esgotamento no meio de cultura: Manitol (Ágar Sal Manitol - Kasvi), para identificação de presença de Staphylococcus; MacConkey (Ágar MacConkey - Kasvi), para identificação de Escherichia; e SS (Ágar Salmonella Shigella - Kasvi), para identificação de Salmonella. Posteriormente, foram levadas para estufa a $37^{\circ} \mathrm{C}$, por um período de 24 a 48 horas (Fig. 3C).

\section{RESULTADOS}

As formigas foram coletadas por meio de armadilhas dispostas em quatro áreas de um pátio de alimentação próximo de uma lanchonete. Todos os pontos de coleta citados apresentaram
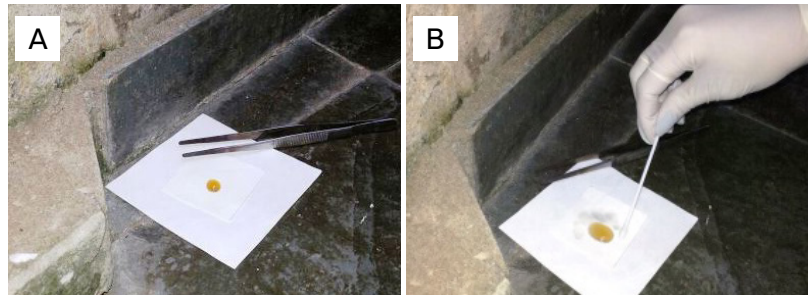

Figura 2. Instalação de uma armadilha: (A) armadilha contendo isca de $2 \mathrm{~mL}$ de mel; (B) coleta do material para análise. circulação de formigas. Das áreas selecionadas como pontos de coleta, duas delas ( 2 e 4) não apresentaram crescimento bacteriano nas etapas de enriquecimento, enquanto as áreas 3 e 4 foram positivas em meios TSA, indicando crescimento de colônias bacterianas (Tabela 1). Após essa etapa, as colônias obtidas foram submetidas à técnica de Gram, em que foram isoladas e transferidas para o meio de enriquecimento (Caldo Triptona de Soja), caracterizando a segunda fase do experimento. Nessa segunda fase, as amostras enriquecidas foram submetidas em meios de cultura de identificação, momento em que apresentaram crescimento de Staphylococcus epidermidis (Tabela 2).

Tabela 1. Resultado da primeira e da segunda fase do experimento.

\begin{tabular}{|c|c|c|c|}
\hline $\begin{array}{l}\text { Amostras } \\
\text { em meio } \\
\text { líquido TSB }\end{array}$ & $\begin{array}{l}\text { Semeadas por } \\
\text { método de } \\
\text { esgotamento } \\
\text { no TSA }\end{array}$ & $\begin{array}{l}\text { Técnica } \\
\text { de gram }\end{array}$ & $\begin{array}{c}\text { Isoladas no } \\
\text { TSB para } \\
\text { enriquecimento }\end{array}$ \\
\hline
\end{tabular}

\begin{tabular}{lccc} 
Ponto 1 & + & G+ & + \\
Ponto 2 & - & - & - \\
Ponto 3 & + & G+ & + \\
Ponto 4 & - & - & - \\
\hline
\end{tabular}

TSB: Caldo Triptona de Soja; TSA: Ágar Triptona de Soja - Kasvi; G+: Gram-positivas; G-: gram-negativas; +: presença de crescimento bacteriano; -: ausência de crescimento bacteriano.

Tabela 2. Resultado da segunda fase: semeadura do Caldo Triptona de Soja (enriquecido) para ágar seletivo por método de esgotamento.

\begin{tabular}{|c|c|c|c|}
\hline Meio & Manitol & MacConkey & SS \\
\hline Amostras & $\begin{array}{c}\text { Identificação de } \\
\text { Staphylococcus } \\
\text { G+ }\end{array}$ & $\begin{array}{c}\text { Identificação } \\
\text { de Escherichia } \\
\text { G- }\end{array}$ & $\begin{array}{l}\text { Identificação } \\
\text { de Salmonella } \\
\text { G- }\end{array}$ \\
\hline Ponto 1 & S. epidermidis & - & - \\
\hline Ponto 3 & S. epidermidis & - & - \\
\hline
\end{tabular}

G+: gram-positivas; G-: gram-negativas; +: presença de crescimento bacteriano; -: ausência de crescimento bacteriano.
A

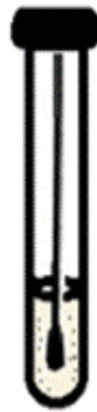

B

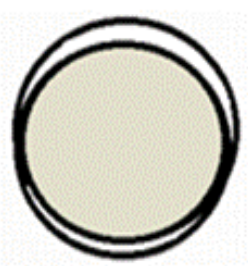

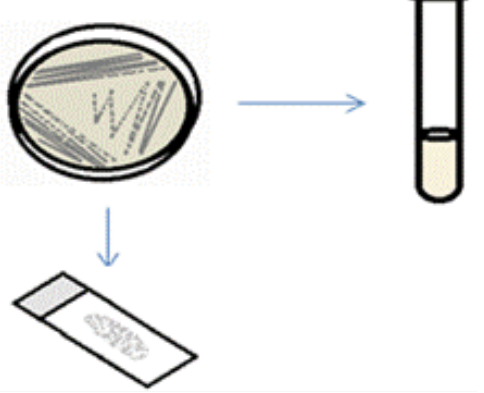

C

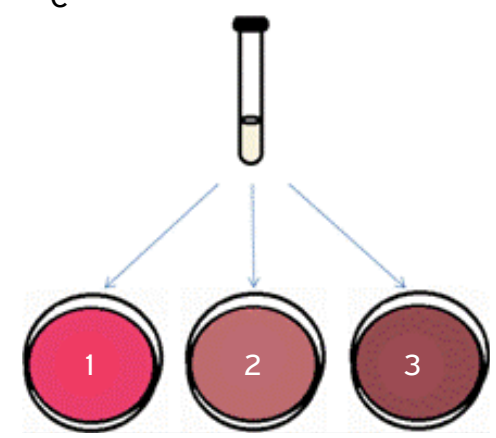

Figura 3. Esquema ilustrativo dos procedimentos realizados: (A) primeira fase do experimento: tubo de coleta com swab e posterior semeadura em TSA; (B) segunda fase do experimento: identificação e isolamento dos grupos gram e transferência, para enriquecimento em Caldo Triptona de Soja; (C) terceira fase do experimento: após enriquecimento, a semeadura em meios seletivos 1) Manitol, 2) SS e 3) MacConkey. 


\section{DISCUSSÃO}

Infecçôes hospitalares estão frequentemente associadas à presença de formigas contaminadas. Por conta de sua vasta área de circulação em busca de alimentos durante todas as estaçôes do ano, tais insetos representam risco à saúde humana (GONÇALVES et al., 2011). Entretanto, poucos trabalhos investigam a contaminação trazida por formigas em restaurantes e lanchonetes.

A espécie $S$. aureus não foi identificada nesta análise, mesmo sendo considerada, de acordo com a literatura, a bactéria mais conhecida e mais patogênica. Além disso, essa espécie está presente em ambientes de convívio comum, podendo representar grande risco de complicaçóes e até de adoecimento para indivíduos com a saúde debilitada (MENDES et al., 2015).

A espécie S. epidermidis predomina na pele e nas mucosas de indivíduos normais, em razáo da sua capacidade de produzir bacteriocinas ativas contra outras bactérias gram-positivas que podem competir por nichos de colonizaçáo.

Até pouco tempo atrás, tal espécie era considerada um contaminante, tendo pouca importância clínica, porém, nas últimas décadas, o $S$. epidermidis tornou-se um principal agente de infecçôes hospitalares, representando aproximadamente 20,9\% dos casos (SAITO et al., 2014; TAJEDDIN et al., 2015).

As infecçôes causadas por $S$. epidermidis são frequentemente subagudas ou crônicas, e o diagnóstico nem sempre é fácil, principalmente em pacientes imunossuprimidos e usuários de drogas intravenosas, passíveis de desenvolver endocardite, e a infecção ocorre por bactérias encontradas na própria pele do paciente (SAITO et al., 2014).

Náo foi identificada a presença de Escherichia sp. nem de Salmonella sp. nos meios de cultura seletivos MacConkey nem SS. A ausência de enterobactérias como a $E$. coli nas formigas analisadas pode ser explicada pelo fato de a área estudada não apresentar ligação direta com sanitários coletivos, dificultando $o$ acesso de formigas andarilhas.
As bactérias do gênero Salmonella também não foram encontradas neste estudo, apesar de a área averiguada ser habitada por pombos comuns do gênero Columba livia. Esses animais, com frequência, apresentam doenças como salmonelose, o que poderia representar risco aos usuários da região estudada (GARGIULO et al., 2014).

Levando em consideração que a pesquisa foi realizada no entorno de uma lanchonete, onde há diariamente grande circulação de pessoas, o resultado encontrado demonstra que a área avaliada, no momento do estudo, não apresenta risco, visto que é devidamente higienizada e apresenta controle de insetos, diminuindo o risco de contaminaçáo por bactérias patogênicas para a população circulante.

Portanto, a coleta e a identificação de patógenos em formigas podem ser ferramentas valiosas para estimar o potencial de contaminação de áreas com grande circulação de pessoas (SCHULLER; MATTÉ; MATTÉ, 2009), além de fornecer indicadores para a melhoria dos procedimentos de higienização e controle bacteriano (BRAGANÇA; LIMA, 2010) e fúngico (AQUINO et al., 2013).

\section{CONCLUSÃO}

Este estudo identificou a presença S. epidermidis em formigas operárias em uma lanchonete localizada em uma área de grande circulação de pessoas, indicando que tais insetos podem ser vetores de contaminaçáo em estabelecimentos de comércio de alimentos.

\section{AGRADECIMENTOS}

Agradecemos ao Laboratório de Microbiologia da Universidade Guarulhos o apoio e o suporte técnico e financeiro.
LAMBRECHTS, A.A.; HUMAN, I.S.; DOUGHARI, J.H.; LUES, J.F.R. Bacterial contamination of the hands of food handlers as indicator of hand washing efficacy in some convenient food industries in South Africa. Pakistan Journal of Medical Sciences, v.30, n.4, p.755-758, 2014.

AQUINO, R.S.; SILVEIRA, S.S.; PESSOA, W.F.; RODRIGUES, A.; ANDRIOLI, J.L.; DELABIE, J.H.; FONTANA, R. Filamentous fungi vectored by ants (Hymenoptera: Formicidae) in a public hospital in North-Eastern Brazil. Journal of Hospital Infection, v.83, n.3, p.200-204, 2013.
BOURSAUX-EUDE, C.; GROSS, R. New insights into symbiotic associations between ants and bacteria. Research in Microbiology, v.151, n.7, p.513-519. 2000.

BRAGANÇA, M.A.; LIMA, J.D. [Composition, abundance and infestation rate of ant species in a children's hospital in the city of Palmas, Tocantins, Brazil]. Neotropical Entomology, v.39, n.1, p.124-130, 2010.

BUCZKOWSKI, G.; RICHMOND, D.S. The effect of urbanization on ant abundance and diversity: a temporal examination of factors affecting biodiversity. PLoS One, v.7, n.8, p.e41729, 2012. 
BUENO, O.C.; CAMPOS-FARINHA, C. As formigas domésticas. In: MARICONI, F.A.M. (Ed). Insetos e outros invasores de residências. Piracicaba: FEALQ, 1999. 460 p.

CERVA, C.; BREMM, C.; REIS, E.M.; BEZERRA, A.V.; LOIKO, M.R.; CRUZ, C.E.; CENCl, A. Food safety in raw milk production: risk factors associated to bacterial DNA contamination. Tropical Animal Health and Production, v.46, n.5, p.877-882, 2014.

CHADEE, D.D.; LE MAITRE, A. Ants: potential mechanical vectors of hospital infections in Trinidad. Transactions of the Royal Society of Tropical Medicine and Hygiene, v.84, n.2, p.297, 1990.

DA COSTA, S.B.; PELLI, A.; DE CARVALHO, G.P.; OLIVEIRA, A.G.; DA SILVA, P.R.; TEIXEIRA, M.M.; MARTINS, E. [Ants as mechanical vectors of microorganisms in the School Hospital of the Universidade Federal do TriânguloMineiro]. Revista da Sociedade Brasileira de Medicina Tropical, v.39, n.6, p.527-529, 2006.

DE WIT, J.C.; KAMPELMACHER, E.H. Some aspects of bacterial contamination of hands of workers in food service establishments. Zentralblatt für Bakteriologie, Mikrobiologie und Hygiene, v.186, n. 1, p.45-54, 1988.

FONTANA, R.; WETLER, R.M.; AQUINO, R.S.; ANDRIOLI, J.L.; QUEIROZ, G.R.; FERREIRA, S.L.; NASCIMENTO, I.C. [Pathogenic bacteria dissemination by ants (Hymenoptera: Formicidae) in two hospitals in northeast Brazil]. Neotropical Entomology, v.39, n.4, p.655-663, 2010.

GARGIULO, A.; RUSSO, T.P.; SCHETTINI, R.; MALLARDO, K.; CALABRIA, M.; MENNA, L.F.; RAIA, P. Occurrence of enteropathogenic bacteria in urban pigeons (Columba livia) in Italy. Vector-Borne and Zoonotic Diseases, v. 14, n.4, p.251-255, 2014.

GIL, A.I.; LANATA, C.F.; HARTINGER, S.M.; MÄUSEZAHL, D.; PADILLA, B.; OCHOA, T.J.; LOZADA, M. Fecal contamination of food, water, hands, and kitchen utensils at the household level in rural areas of Peru. Journal of Environmental Health, v.76, n.6, p.102-106, 2014.

GONÇALVES, M.G.; LOECK, A.E.; SILVA, E.J.E.; SILVA, W.P.; ROSADO, J.L.O.; BASTOS, C.P.; BASSANI, M.T. Associação entre formigas (Hymenoptera: Formidae) e bactérias patogênicas em cinco hospitais do município de pelotas, RS. Arquivos do Instituto de Biologia, v.78, p.287-295, 2011.
HO, J.; BOOST, M.; O'DONOGHUE, M. Sustainable reduction of nasal colonization and hand contamination with Staphylococcus aureus in food handlers, 2002-201 1. Epidemiology and Infection, v.143, n.8, p.1751-1760, 2015.

MÁXIMO, H.J.; FELIZATTI, H.L.; CECCATO, M.; CINTRASOCOLOWSKI, P.; BERETTA, A.L. Ants as vectors of pathogenic microorganisms in a hospital in São Paulo county, Brazil. BMC Research Notes, v.7, p.554, 2014.

MENDES, Â.; MARTINS DA COSTA, P.; REGO, D.; BEÇA, N.; ALVES, C.; MOREIRA, T.; CONCEIÇÃO, T. Contamination of public transports by Staphylococcus aureus and its carriage by biomedical students: point-prevalence, related risk factors and molecular characterization of methicillin-resistant strains. Public Health, v.129, n.8, p.1125-1131, 2015.

MIRZAEI, R.; SHAHRIARY, E.; QURESHI, M.I.; RAKHSHKHORSHID, A.; KHAMMARY, A.; MOHAMMADI, M. Quantitative and qualitative evaluation of bio-aerosols in surgery rooms and emergency department of an educational hospital. Jundishapur Journal of Microbiology, v.7, n.10, p.e1 1688, 2014.

PESQUERO, M.A.; ELIAS FILHO, J.; CARNEIRO, L.C.; FEITOSA, S.B.; OLIVEIRA, M.A.; QUINTANA, R.C. [Ants in a hospital environment and its importance as vector of bacteria]. Neotropical Entomology, v.37, n.4, p.472-477, 2008.

SAITO, Y.; KOBAYASHI, H.; UETERA, Y.; YASUHARA, H.; KAJIURA, T.; OKUBO, T. Microbial contamination of surgical instruments used for laparotomy. American Journal of Infection Control, v.42, n. 1, p.43-47, 2014.

SALYER, A.; BENNETT, G.W.; BUCZKOWSKI, G.A. Odorous house ants (Tapinoma sessile) as back-seat drivers of localized ant decline in urban habitats. PLoS One, v.9, n.12, p.e113878, 2014.

SCHULLER, L.; MATTÉ, G.R.; MATTÉ, M.H. A new sterile technique effective on capturing tramp ants for microbiological investigations. Neotropical Entomology, v.38, n.4, p.560-563, 2009.

TAJEDDIN, E.; RASHIDAN, M.; RAZAGHI, M.; SEYED JAVADI, S.S.; JAHANI SHERAFAT, S.; ALEBOUYEH, M.; SARBAZI, M.R. The role of the intensive care unit environment and health-care workers in the transmission of bacteria associated with hospital acquired infections. Journal of Infection and Public Health, v.9, n. 1, p.13-23, 2015. 